\title{
Neonatal Hypopituitarism: Unusual Presentation
}

\author{
Abdulsalam Abu-Libdeh ${ }^{1} \quad$ Bassam Abu-Libdeh $^{1} \quad$ Ulla Najwa Abdulhag ${ }^{1}$ \\ ${ }^{1}$ Department of Pediatrics, Makassed Islamic Hospital, \\ Jerusalem, Israel \\ J Child Sci 2017;7:e103-e105.

\begin{abstract}
Address for correspondence Abdulsalam Abu-Libdeh, MD, Department of Pediatrics, Makassed Islamic Hospital, P.O.Box 19482, Mount of Olives, Jerusalem, Israel

(e-mail: abdulsalam@hadassah.org.il).
\end{abstract}

\begin{abstract}
Keywords

- cholestasis

- panhypopituitarism

- hemochromatosis

Objective We report an infant with panhypopituitarism presenting with cholestatic jaundice, hypoglycemia, and high ferritin level.

Methods We conducted clinical and laboratory investigations, including metabolic, infectious, and hormonal evaluation.

Results Hormonal evaluation revealed panhypopituitarism (cortisol deficiency, growth hormone deficiency, and central hypothyroidism). Other causes of cholestasis were ruled out. Surprisingly, serum ferritin level was very high suggesting neonatal hemochromatosis, which was ruled out by the absence of hemosiderin deposition in buccal mucosal biopsy. Replacement therapy with glucocorticoids and L-thyroxin showed improvement of liver function tests, resolved cholestatic jaundice, and significantly decreased serum ferritin level. These findings support the assumption that thyroid hormone and cortisol affect the bile acid-independent bile flow.

Conclusion This is the first description of an infant with congenital panhypopituitarism, presenting with cholestasis, hypoglycemia, and high serum ferritin level. Panhypopituitarism should be considered in any infant who presents with cholestasis, hypoglycemia, and other manifestations of pituitary malfunction. High serum ferritin level probably reflects acute phase reaction.
\end{abstract}

\section{Introduction}

Congenital hypopituitarism is a rare condition associated with possible serious complications and long-term neurological sequelae, if not promptly recognized and treated. ${ }^{1}$

Neonates with congenital hypopituitarism may present with or without associated developmental defects, such as ocular, midline, and genital abnormalities. They may also present with nonspecific symptoms, including hypoglycemia, lethargy, apnea, hemodynamic instability, jitteriness, seizures, poor weight gain, failure to thrive, temperature instability, micropenis, recurrent sepsis, neonatal cholestasis, and prolonged jaundice. ${ }^{1,2}$

Hypoglycemia due to panhypopituitarism is typically detected shortly after birth, but it may occur several weeks after the neonatal period. ${ }^{3}$

Herman et al first postulated that the hormonal deficiencies due to congenital panhypopituitarism were the cause of neonatal cholestasis. ${ }^{4}$ Although the causes are still unknown and the incidence is low, it is still crucial to evaluate any cholestatic infant to prevent progressive hepatic disease and neurological complications.

The cholestatic jaundice most commonly associated with neonatal hypopituitarism manifests as conjugated hyperbilirubinemia with elevated alkaline phosphatase titers. ${ }^{4,5}$ The pathogenesis of cholestasis is unclear. The cholestasis resolves after replacement of glucocorticoids or growth hormone, suggesting a role of these hormones in biliary excretory function. ${ }^{6}$

We report an infant with congenital panhypopituitarism presenting with cholestasis, hypoglycemia, and high serum ferritin level, suggesting neonatal hemochromatosis.

\section{Case Report}

A 7-week-old female infant, born to consanguineous Palestinian parents, with uneventful pregnancy and delivery and birth weight of $3.2 \mathrm{~kg}$, presented with prolonged cholestatic jaundice, received

March 24, 2017

accepted after revision

June 23, 2017
DOI https://doi.org/

10.1055/s-0037-1604449.

ISSN 2474-5871.
Copyright (c) 2017 Georg Thieme Verlag License terms

KG Stuttgart · New York

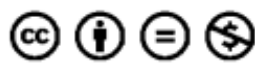


recurrent attacks of hypoglycemia since early infancy, and inadequate weight gain. Physical examination revealed jaundice, dark-colored skin, and hepatomegaly. Metabolic, infectious, and hormonal workups were performed. Laboratory investigations revealed elevated transaminase levels and surprisingly very high serum ferritin level of $2,315 \mathrm{ng} / \mathrm{mL}$, suggesting neonatal hemochromatosis.

Urinalysis for reducing substances was negative; vertebral $\mathrm{X}$-ray and ophthalmic examination were normal; TORCH (toxoplasmosis, rubella cytomegalovirus, herpes virus, and HIV) evaluation was negative; serum amino acid and alpha-1 antitrypsin levels were normal. Abdominal ultrasound revealed hepatomegaly.

Neonatal hemochromatosis was ruled out by buccal mucosa biopsy that did not show hemosiderin deposition.

Critical sample during hypoglycemia revealed inappropriately low growth hormone $(\mathrm{GH})$ and cortisol levels (cortisol level, $0.02 \mu \mathrm{g} / \mathrm{dL}$ and growth hormone, $8.1 \mathrm{ng} / \mathrm{mL}$ ). Growth hormone stimulation tests with arginine and clonidine were consistent with GH deficiency. Adrenocorticotropin (ACTH) stimulation test showed significant cortisol deficiency. Hormonal screening revealed central hypothyroidism. Brain magnetic resonance imaging (MRI) showed mild widening of the bifrontal cerebrospinal fluid (CSF) spaces and normal appearance of the pituitary with bright spot in place.

The patient was started on hormone replacement therapy (HRT) as soon as the diagnosis was made with hydrocortisone $15 \mathrm{mg} / \mathrm{m}^{2}$ daily. Then, L-thyroxin was added, after which the patient showed significant improvement. Blood tests revealed decreased ferritin levels, liver function tests turned to normal within 2 months of treatment, and weight increased significantly. Hepatomegaly resolved and no further episodes of hypoglycemia were reported. $\mathrm{GH}$ was not started immediately in spite of the fact that it has an extensive action on metabolism, including liver and carbohydrate metabolism. As the patient improved dramatically, it was started later (before waiting for growth failure).

Laboratory results for this patient are summarized in - Table 1 (before and after 2 months of treatment).

\section{Discussion}

Factors predisposing neonatal cholestasis include immaturity of hepatic excretory function, inborn errors of metabolism, an inherent susceptibility to viral or toxic insult, and a stereotypic response of the immature hepatocyte to injury. The condition demands urgent attention to identify treatable conditions to prevent progressive hepatic disease and neurologic complications.

Panhypopituitarism can present with many symptoms, including cholestasis as the initial presenting symptom. ${ }^{6}$ Common clinical presentation of $\mathrm{GH}$ deficiency in the newborn is hypoglycemia; GH deficiency is also commonly associated with hypopituitarism. ${ }^{7}$

The link between hypopituitarism and associated cholestasis is not well understood. However, lack of GH may affect liver function through decreased bile acid synthesis and
Table 1 Lab results before and after treatment

\begin{tabular}{|l|l|l|}
\hline $\begin{array}{l}\text { Test and normal } \\
\text { range for age }\end{array}$ & $\begin{array}{l}\text { Before } \\
\text { treatment } \\
\text { (7 wk) }\end{array}$ & $\begin{array}{l}\text { After } \\
\text { treatment } \\
\text { (4 mo) }\end{array}$ \\
\hline AST (15-60) & $372 \mathrm{U} / \mathrm{L}$ & $32 \mathrm{U} / \mathrm{L}$ \\
\hline ALT (13-45) & $110 \mathrm{U} / \mathrm{L}$ & $12 \mathrm{U} / \mathrm{L}$ \\
\hline $\begin{array}{l}\text { Alkaline phosphatase } \\
(150-420)\end{array}$ & $680 \mathrm{U} / \mathrm{L}$ & $359 \mathrm{U} / \mathrm{L}$ \\
\hline Total bilirubin $(<21)$ & $20.1 \mathrm{mg} / \mathrm{dL}$ & $0.7 \mathrm{mg} / \mathrm{dL}$ \\
\hline Direct bilirubin $(<3.4)$ & $13.9 \mathrm{mg} / \mathrm{dL}$ & $0.1 \mathrm{mg} / \mathrm{dL}$ \\
\hline Ferritin (112-450) & $2,315 \mathrm{ng} / \mathrm{mL}$ & $58.42 \mathrm{ng} / \mathrm{mL}$ \\
\hline TSH (0.6-63) & $5.2 \mathrm{mU} / \mathrm{L}$ & $3.0 \mathrm{mU} / \mathrm{L}$ \\
\hline FT4 (10-26) & $9.1 \mathrm{pmol} / \mathrm{L}$ & $18.02 \mathrm{pmol} / \mathrm{L}$ \\
\hline Prolactin (4.1-28.9) & $178 \mathrm{ng} / \mathrm{mL}$ & $18 \mathrm{ng} / \mathrm{mL}$ \\
\hline LH (prepubertal) & $<0.1 \mathrm{IU} / \mathrm{L}$ & $<0.1 \mathrm{U} / \mathrm{L}$ \\
\hline FSH (prepubertal) & $<0.1 \mathrm{mIU} / \mathrm{L}$ & $<0.1 \mathrm{mlU} / \mathrm{L}$ \\
\hline
\end{tabular}

Abbreviations: ALT, alanine aminotransferase; AST, aspartate aminotransferase; FSH, follicle-stimulating hormone; FT4, free thyroxine; LH, luteinizing hormone; TSH, thyroid-stimulating hormone.

structural abnormalities of the bile canaliculi. ${ }^{6}$ Cortisol deficiency can also cause neonatal cholestatic hepatitis. ${ }^{8}$

The association of liver dysfunction with hypopituitarism was first suggested in $1956 .{ }^{9}$ Since then, a few reports have associated neonatal hepatitis with idiopathic hypopituitarism. $^{3-6,10}$ The mechanism of liver dysfunction and the development of cholestasis in hypopituitarism are still the subjects of debate. Isolated thyroid hormone, thyroid stimulating hormone (TSH), GH, ACTH, and cortisol deficiencies have been shown to cause conjugated hyperbilirubinemia but combined deficiencies have also been described. ${ }^{10-13}$

Experiments have demonstrated that cortisol can influence bile formation. Reduced bile flow has been observed in rats after adrenalectomy. ${ }^{14,15}$ Hydrocortisone replacement therapy can resolve cholestatic jaundice in patients. ${ }^{4}$

Prolonged jaundice in a newborn is an indicator to test thyroxine, since TSH deficiency can be a cause of jaundice and a possible indicator of panhypopituitarism if other pituitary hormones are deficient as well. ${ }^{1}$

$\mathrm{GH}$ has been shown to modulate bile acid synthesis in both rats and humans. ${ }^{16}$ Giacoia et al suggested that growth hormone was necessary for bile acid secretion rather than synthesis. ${ }^{11}$ Hodges et al studied the composition of micellar phase during digestion of two consecutive meals in $\mathrm{GH}$ deficient and control patients before and after HRT with GH replacement. ${ }^{16}$ They concluded that HRT with GH increased the hepatobiliary secretion of bile acids and postulated that $\mathrm{GH}$ influences hepatic bile acid biosynthesis.

The fact that jaundice improves after HRT suggests that pituitary hormone deficiency may be related to the pathogenesis of cholestasis. Sheehan et al claimed that the deficiency of one or more hormones in patients with pituitary hypofunction could either delay the normal maturation of 
hepatic active transport mechanisms or inhibit bile acid synthesis, thereby promoting the accumulation of bile acid precursors and producing a cholestatic effect. ${ }^{15}$

In our case, the improvement of cholestasis with HRT over a 5-week-period supports the role of pituitary hormones in bile acid biosynthesis. However, the patient's high ferritin level, which was not secondary to neonatal hemochromatosis and improved dramatically with HRT, is unusual, and raises questions regarding its pathophysiology. To our knowledge, this is the first description of neonatal hypopituitarism presenting with high ferritin level suggesting neonatal hemochromatosis, and improving dramatically on HRT, indicating an acute phase reactant condition.

In conclusion, the nonspecific features of congenital hypopituitarism require a high index of suspicion, particularly in light of this unusual presentation, to reach a diagnosis. Timely treatment of this condition with HRT is required to prevent serious sequelae.

\section{References}

1 Scommegna S, Galeazzi D, Picone S, et al. Neonatal identification of pituitary aplasia: a life-saving diagnosis. Review of five cases. Horm Res 2004;62(01):10-16

2 Kaufman FR, Costin G, Thomas DW, Sinatra FR, Roe TF, Neustein HB. Neonatal cholestasis and hypopituitarism. Arch Dis Child 1984;59(08):787-789

3 Xinias I, Papadopoulou M, Papastavrou T, Patsiaoura K, Spiroglou K. Optic nerve hypoplasia and growth hormone deficiency in a cholestatic infant. Pediatr Neurol 2006;34(04):319-322

4 Herman SP, Baggenstoss AH, Cloutier MD. Liver dysfunction and histologic abnormalities in neonatal hypopituitarism. J Pediatr 1975;87(6, Pt 1):892-895
5 Copeland KC, Franks RC, Ramamurthy R. Neonatal hyperbilirubinemia and hypoglycemia in congenital hypopituitarism. Clin Pediatr (Phila) 1981;20(08):523-526

6 Binder G, Martin DD, Kanther I, Schwarze CP, Ranke MB. The course of neonatal cholestasis in congenital combined pituitary hormone deficiency. J Pediatr Endocrinol Metab 2007;20(06): 695-702

7 Bell JJ, August GP, Blethen SL, Baptista J. Neonatal hypoglycemia in a growth hormone registry: incidence and pathogenesis. J Pediatr Endocrinol Metab 2004;17(04):629-635

8 Gönç EN, Kandemir N, Andiran N, Ozön A, Yordam N. Cholestatic hepatitis as a result of severe cortisol deficiency in early infancy: report of two cases and review of literature. Turk J Pediatr 2006; 48(04):376-379

9 Blizzard RM, Alberts M. Hypopituitarism, hypoadrenalism, and hypogonadism in the newborn infant. J Pediatr 1956;48(06): 782-792

10 DeSalvo D, Pohl JF, Wilson DP, et al. Cholestasis secondary to panhypopituitarism in an infant. J Natl Med Assoc 2008;100(03): 342-344

11 Giacoia GP, MacGillivray MH. Neonatal hypothalamic hypopituitarism and liver dysfunction. N Y State J Med 1981;81(11): 1652-1655

12 Lanes R, Blanchette V, Edwin C, et al. Congenital hypopituitarism and conjugated hyperbilirubinemia in two infants. Am J Dis Child 1978;132(09):926-928

13 Pulichino AM, Vallette-Kasic S, Couture C, et al. Human and mouse TPIT gene mutations cause early onset pituitary ACTH deficiency. Genes Dev 2003;17(06):711-716

14 Bauman JW Jr, Chang BS, Hall FR. The effects of adrenalectomy and hypophysectomy on bile flow in the rat. Acta Endocrinol (Copenh) 1966;52(03):404-408

15 Sheehan AG, Martin SR, Stephure D, Scott RB. Neonatal cholestasis, hypoglycemia, and congenital hypopituitarism. J Pediatr Gastroenterol Nutr 1992;14(04):426-430

16 Hodges S, Buckler JMH. Neonatal cholestasis and hypopituitarism. Arch Dis Child 1984;59(12):1200 